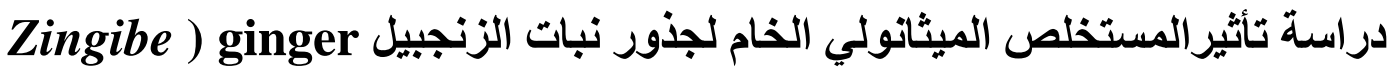

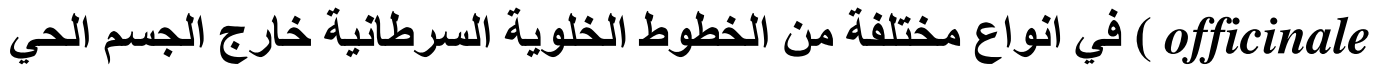

\section{The effect of crude methanolic extract of ginger (Zingibe officinale) root in different cell lines in vitro}

\author{
شيماء اسماعيل كاظم ، صفاء الاين احمد شنتر القيسي

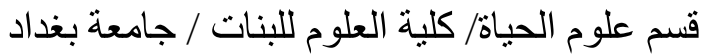

\section{Safaa Al-deen Ahmed Alqysi , Shamaa Ismael Kadhum}

Biology Dept./ College of Science for women / Baghdad University

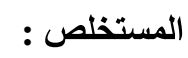

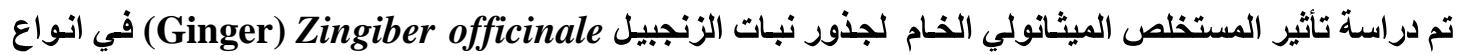

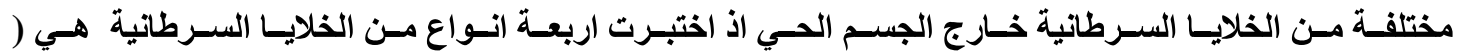

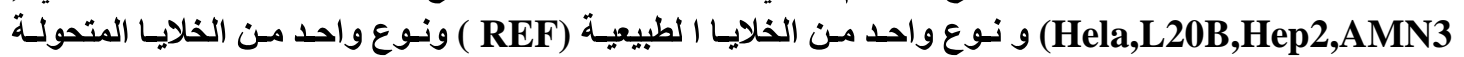

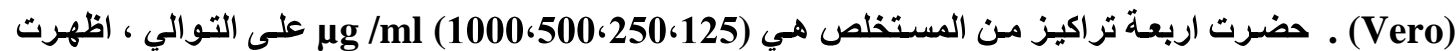

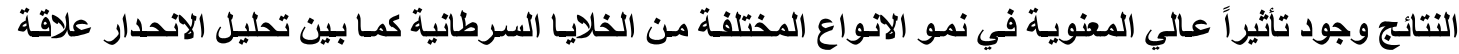

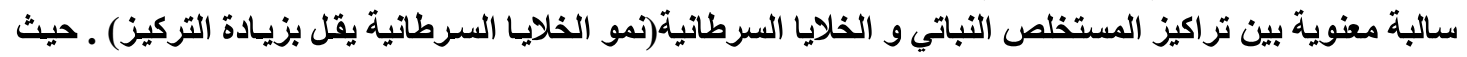

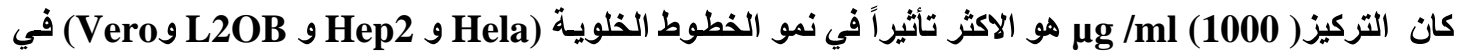

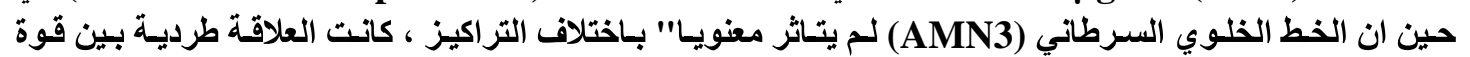
التركيز ومعدل تتبيط الخلايا المدروسة اذ كان تاثر الخلايا الطبيعية اكثر وضوحا مقارنة بالخطوط الخلوية السرطانية

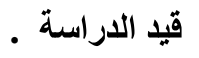

\section{Abstract}

This study involved the affectivity of crude methanolic extract of ginger root on different cells line in vitro, four cancer cell lines were tested Hela, L20B,Hep2, AMN3 compared with normal cell line (REF)and transformed cell line (Vero). Four extract concentrations were prepared $(125,250,500,1000) \mu \mathrm{g} / \mathrm{ml}$ respectively, the results showed a significant inhibitory effect on the growth of different cell lines under study, also regression showed a significant negative relationship between plant extract and cell lines, $1000 \mu \mathrm{g} / \mathrm{ml}$ concentration showed significant effect on cell lines growth (HELA,Hep2,L20B and Vero) on the other hand AMN3 was not affected by the plant extract, there was a direct relationship between concentrations and the rate of inhibition of the cell lines, on the other hand the normal cell line were more effected than cancer cell lines under study.

تز ايد الاهتمام في الاونة الاخيرة بدر اسة المستخلصـات النباتيـة ومركباتها الفعالةوت تأثير هذه المركبات التي هي عبارة

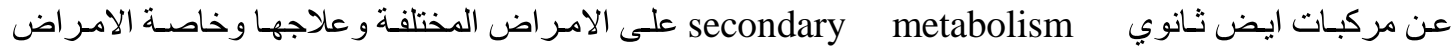


المستعصية التي لم يتوصل العلم لأيجاد العلاج الناجع لهاومن امثلتها السرطانات المختلفة [1] ويمكن تعريف السرطان

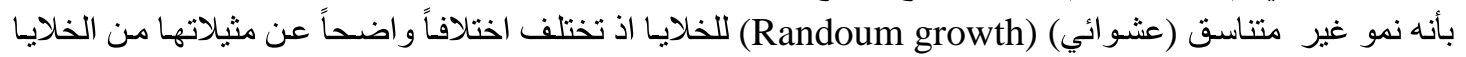

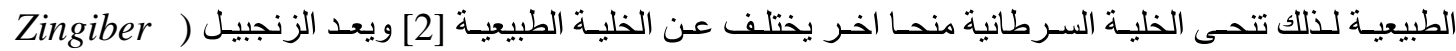
(officinale

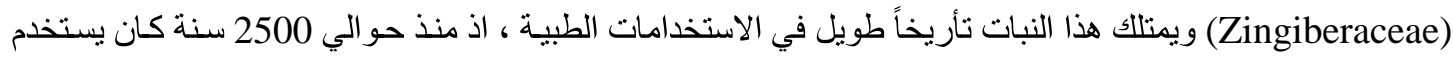

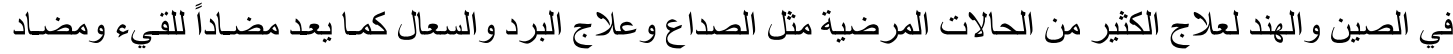

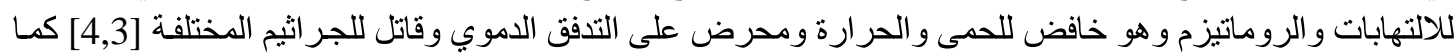

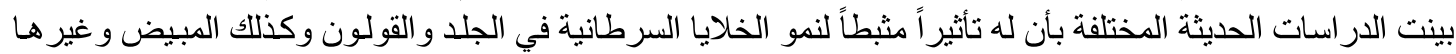

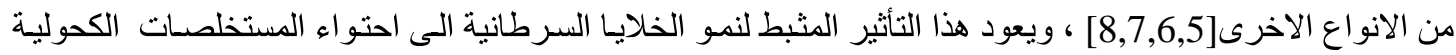

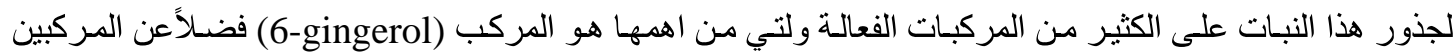

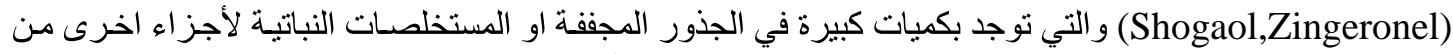

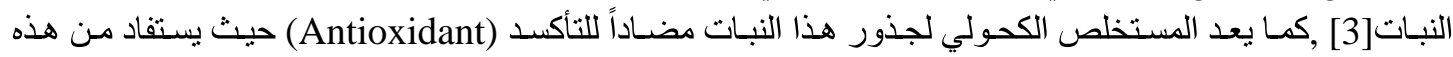

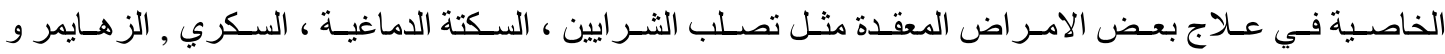
السرطان[10,9]

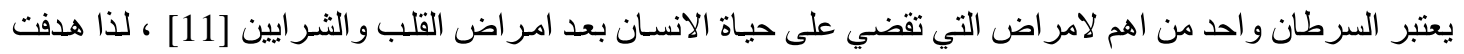

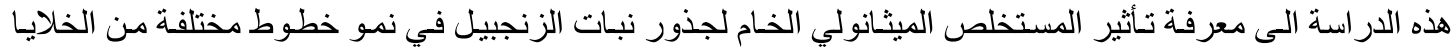

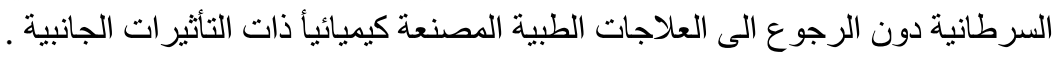

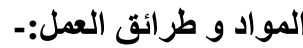

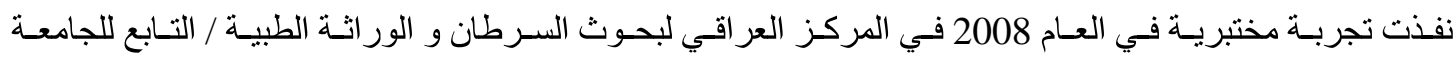

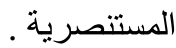

1.الخطوط الخلوية :- تم الحصول على خطوط الخلايا السرطانية من المركز اعلاه

1- AMN-3( Ahmed-Mahmad-Nahi-2003) .

2 Hep2-(Human eipoermoid larynx carcinoma)

3-Hela-(Cancer cells from human female cervix)

4-L20B ( Fibroblast muscle cell)

5-Vero-(African green monkey kidney transfer cell )

6- REF ( Rabbit Embryo Fibroblast )

فضلاً عن خط الخلايا الطبيعي

2.المستخلص النباتي:-

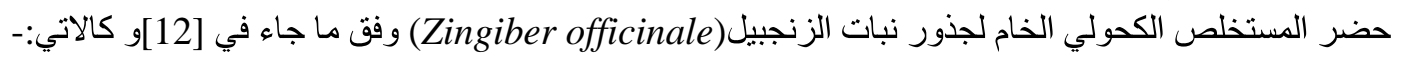

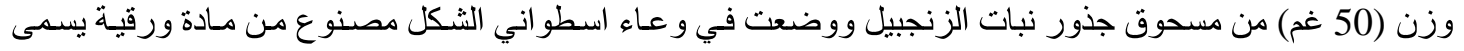

. Thimble

وضع Thimble في المكان المخصص له في جهاز الاستخلاص المستمر وتركت العينة لمدة 24 في الميثانول لكي يتشرب المسحوق بالمذيب .

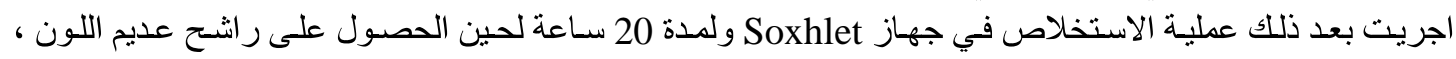
وبعدها رشح المستخلص بورق ترشيح(1) .Whatman No.

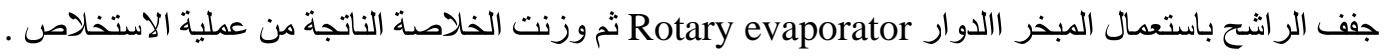

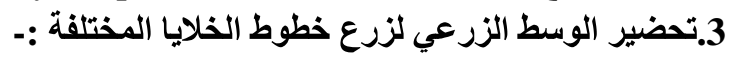

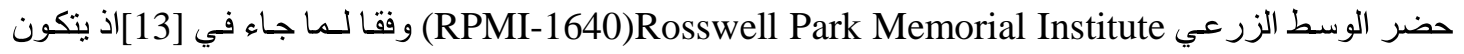
الوسط الزرعي من:- 
RPMI-1460 with hepes buffer ,L-glutamin 10.4 gm

Crystaline penicillin $0.5 \mathrm{ml}$

Streptomycin $0.5 \mathrm{ml}$

Bovine calf serum $10 \%$

Sodium bicarbonate $4.4 \%$

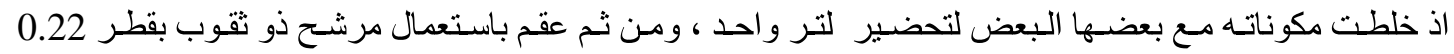

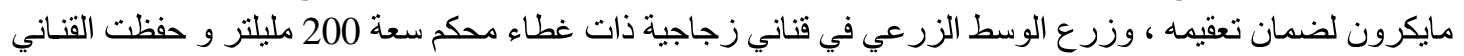
بدرجة 2 م لحين الاستعمال . اضيف 2 مليلتر من محلول التربسين/ فرسين الى قنتينة الزرع النسيجي حجم 25سم الحاوية على الخلايا (الانواع

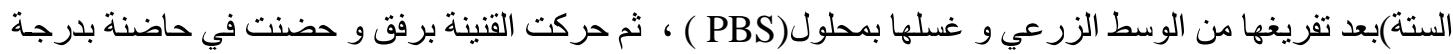
37م لمدة 15 دقيقة لتفكبك الخلايا الملتصقة و كذلك خلخلت التصـاقها بجدار القنينية للحصول قدر الامكان على خلايـا

ا احادية مفردة .

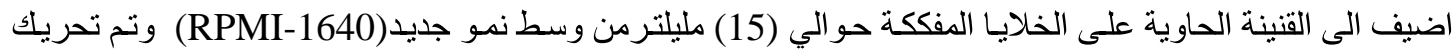

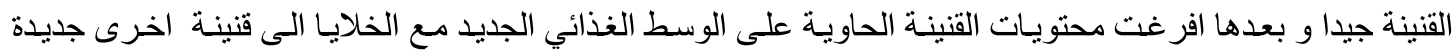

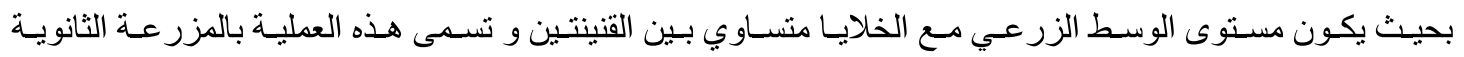

.( Subculture)

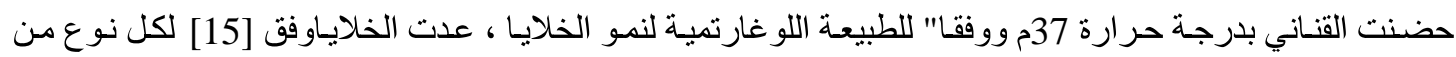

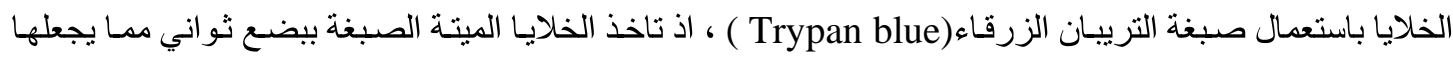

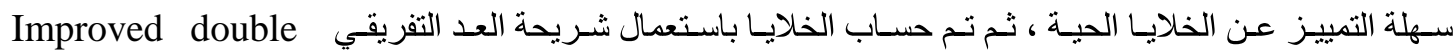

.Neubauer ruling

4.اختبار سمية المستخلصات الخام في نمو الخطوط الخلوية السرطانية والخط الطبيعي :-

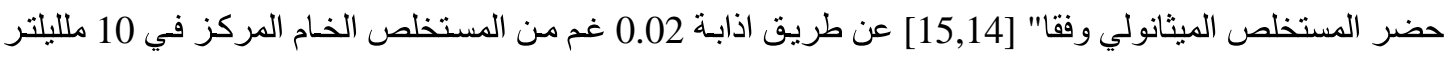
من الـذيب (Dimethyl Sulf Oxide (DMSO المطلق + DPM ) serum free media) وهو الوسط الزرعي

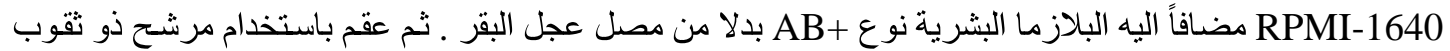

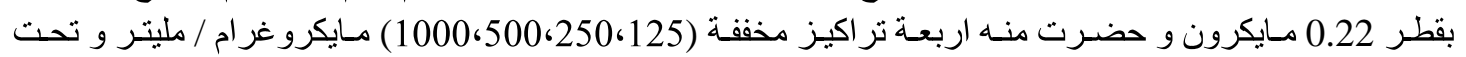

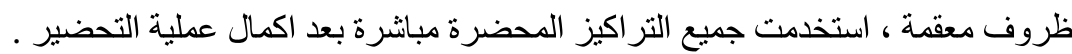

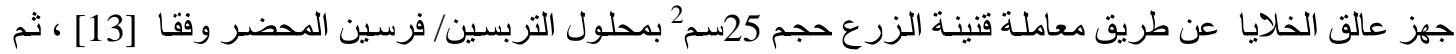

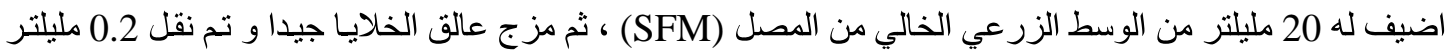

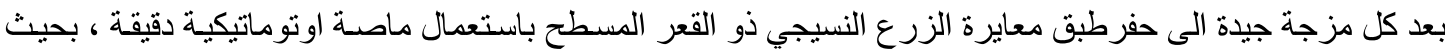

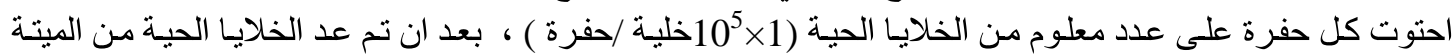

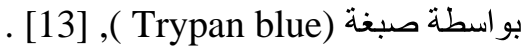

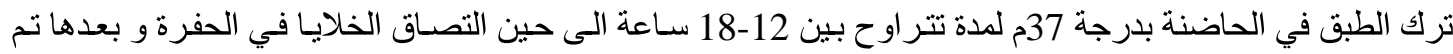

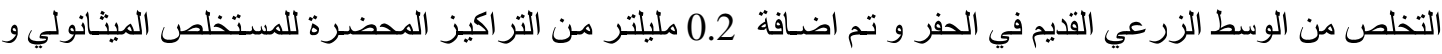

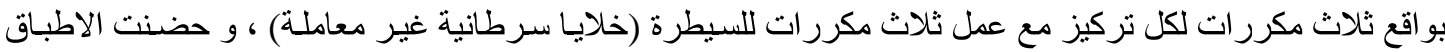

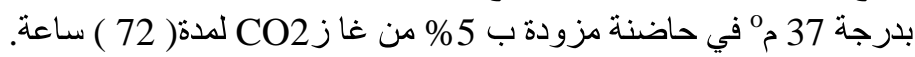

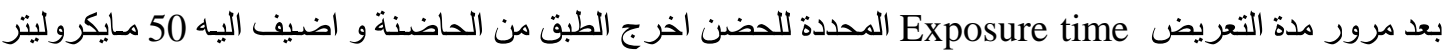

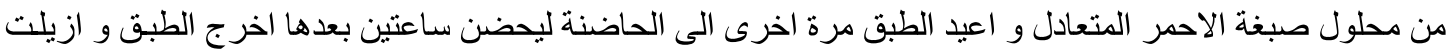

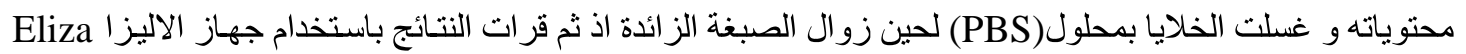

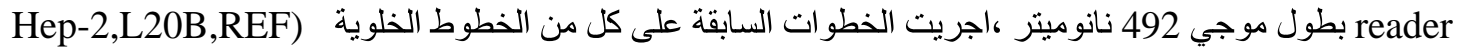
، باستعمال التر اكيز المختلفة للمستخلص الخام . ل 
التحليل الاحصائي:

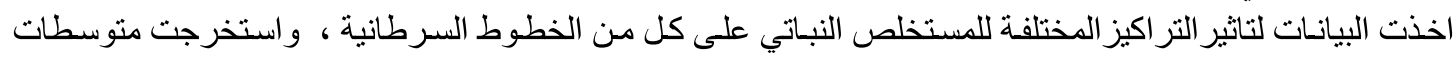

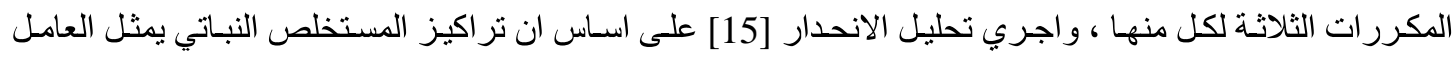

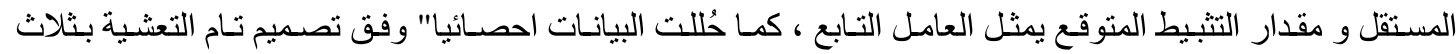

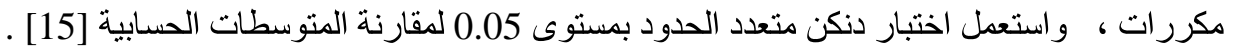

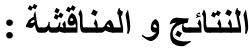

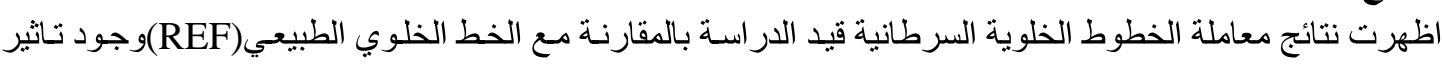

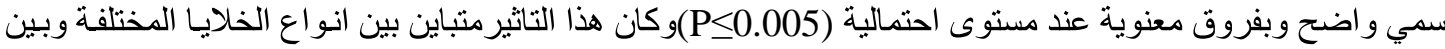
التر اكيز المختلفة وكما يأتي:-

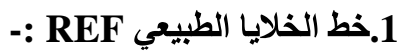

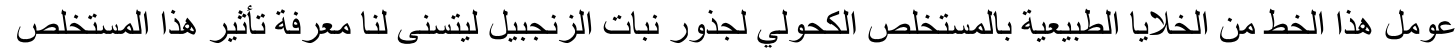

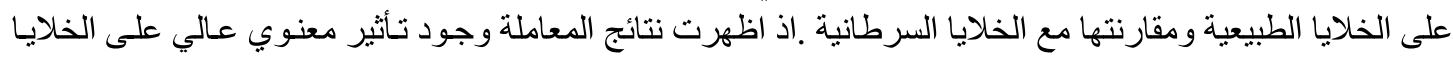
الطبيعية عند التر اكيز العالية من المستخلص وبالنسبة للتركيز 125 مـايكروغ /مل فيل فكان التأثير معنوي مقارنـة بمعاملـة

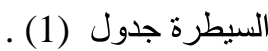

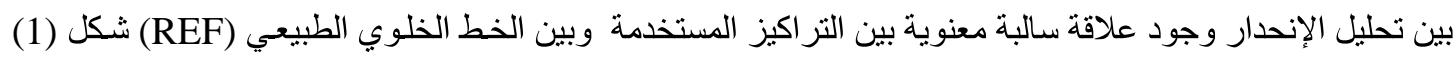

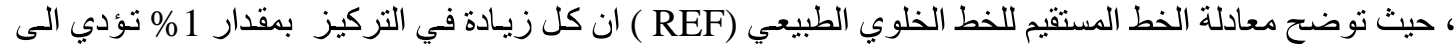
تثبيط في معدل نمو الخط الخلوي الطبيعي بمقداريط \%0.76\% شكل (2) . فحسب معادلة التوقع التي يوضحها شكل (1) .

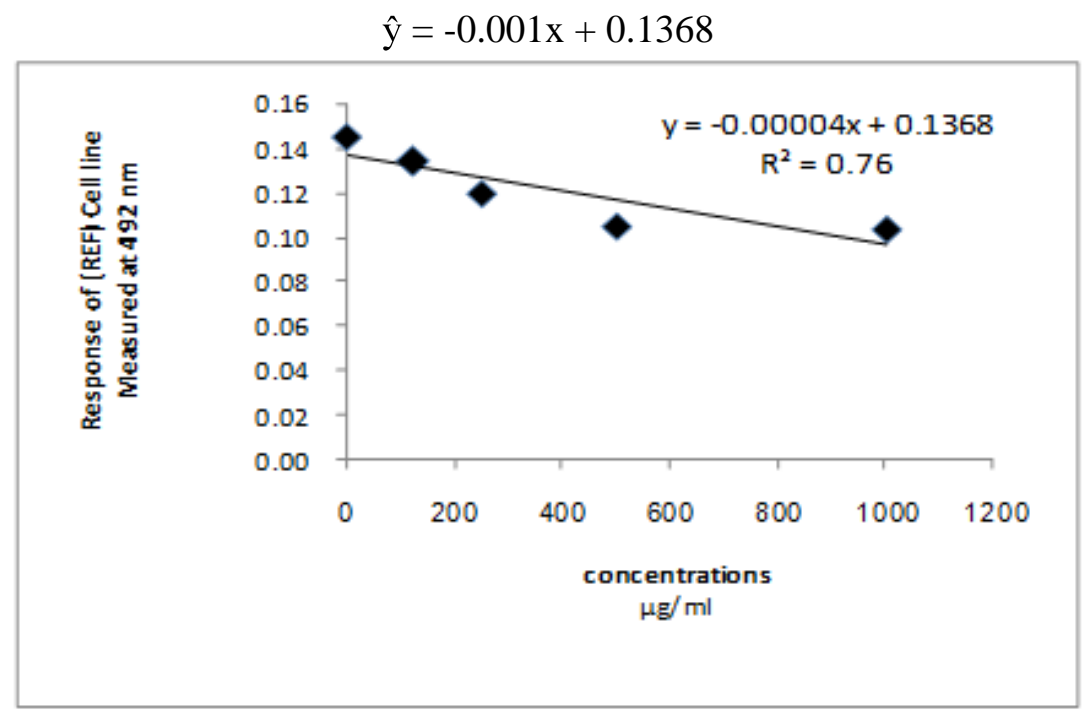

شكل(1) علاقة الانحدار بين تراكيز المستخلص النباتي و الخط الخلوي الطبيعي REF

فأن حصولنا على تركيز مناسب يؤدي الى تثببط في نمو الخط الطبيعي يصل الى (1000مايكرو غر ام/مليلتر ) و

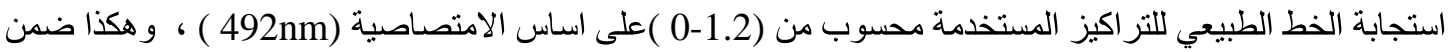

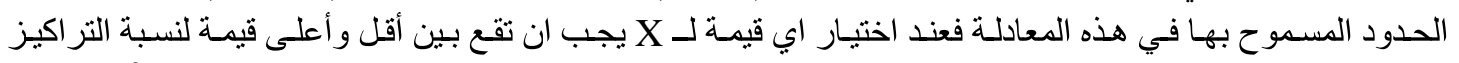

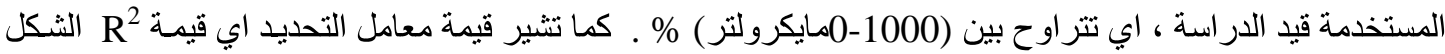

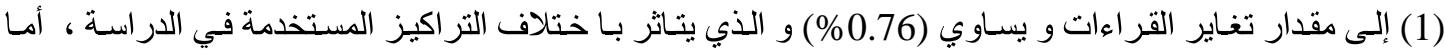

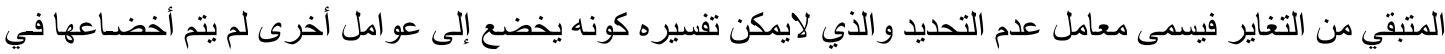

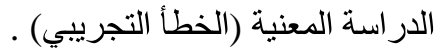




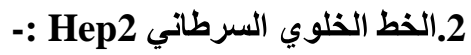

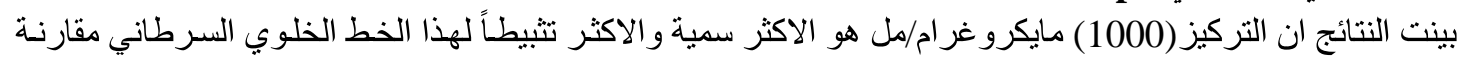

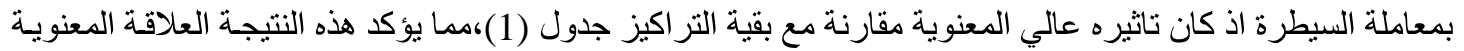

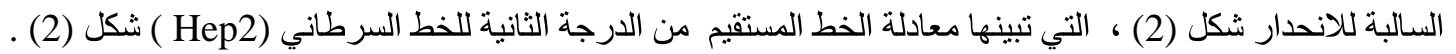

$$
R^{2}=0.97 \% \text { وقيمة معامل التحديد قيمة y }
$$

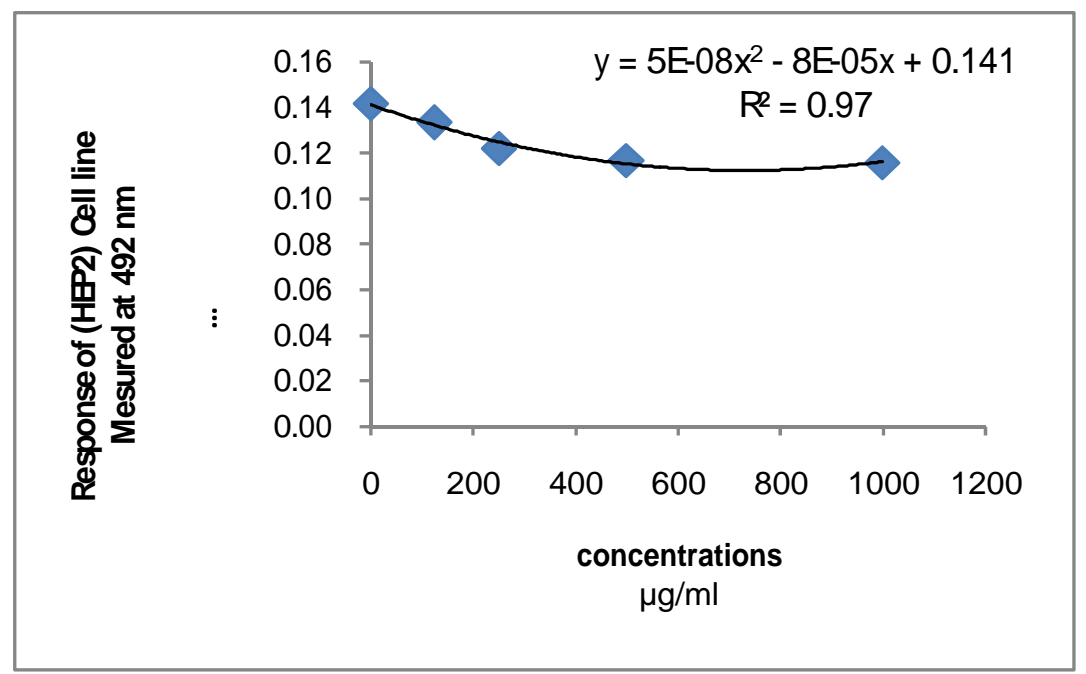

شكل(2) علاقة الانحار بين تراكيز المستخلص النباتي والخط الظلوي السرطاني HEP2

3.الخط الخلوي المتحول Vero :-

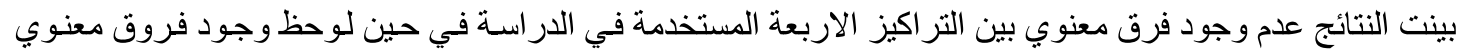

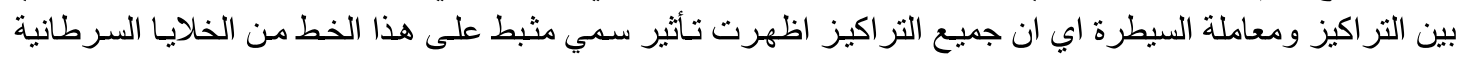

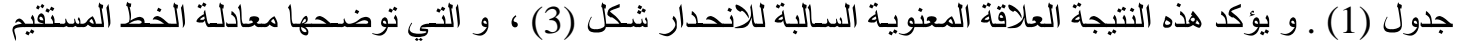

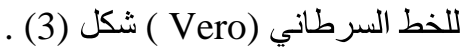

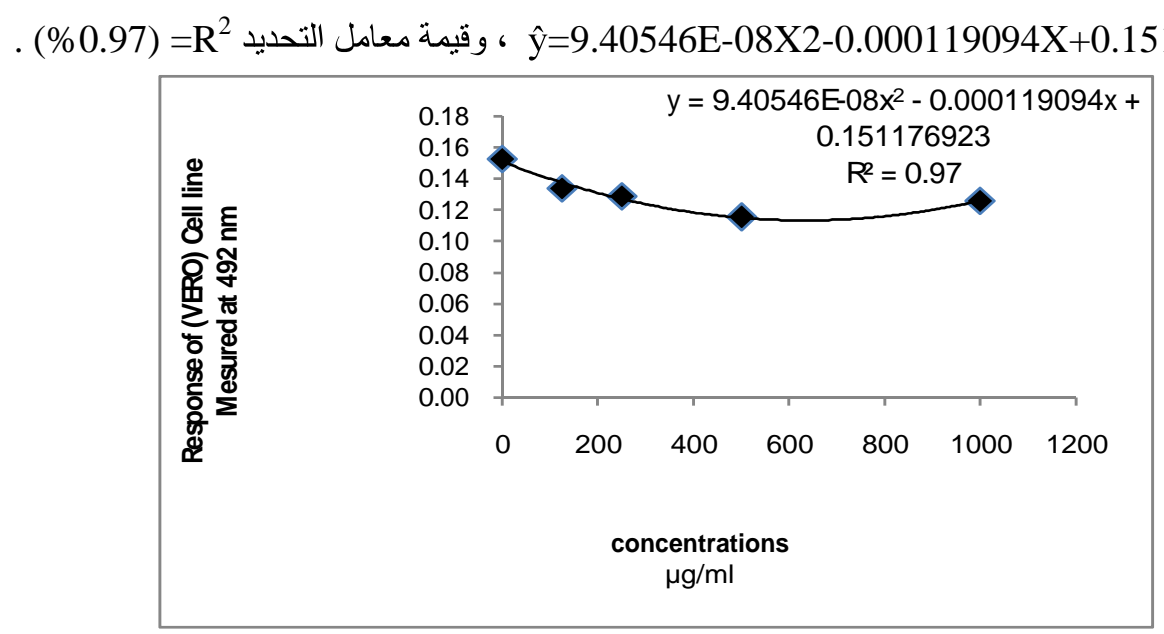

شكل(3) علاقة الاتحدار بين تراكيز المستخلص النباتي والخط الخلوي المتحول VERO 
جدول (1)يبين تأثير تراكيز مستخلص نبات الزنجبيل في انواع خطوط الخلايا السرطانية قيد الدراسة

\begin{tabular}{|c|c|c|c|c|c|c|}
\hline \multicolumn{6}{|c|}{ قر اءات الخطوط السرطانية } & \multirow{2}{*}{ مايكرو غر ام/مليلتر } \\
\hline REF & L20B & VERO & HELA & AMN3 & HEP2 & \\
\hline $0.145^{\mathrm{a}}$ & $0.142^{\mathrm{a}}$ & $0.153^{\mathrm{a}}$ & $0.1515^{\mathrm{a}}$ & $0.161^{\mathrm{a}}$ & $0.142^{\mathrm{a}}$ & 0 \\
\hline $0.134^{\mathrm{b}}$ & $0.133^{b}$ & $0.134^{b}$ & $0.1350^{b}$ & $0.160^{\mathrm{a}}$ & $0.133^{b}$ & 125 \\
\hline $0.120^{\mathrm{c}}$ & $0.122^{\mathrm{c}}$ & $0.129^{b}$ & $0.128^{b}$ & $0.156^{\mathrm{a}}$ & $0.122^{\mathrm{c}}$ & 250 \\
\hline $0105^{d}$ & $0.117^{\mathrm{c}}$ & $0.126^{b}$ & $0.115^{c}$ & $0.148^{\mathrm{a}}$ & $0.117^{\mathrm{c}}$ & 500 \\
\hline $0.104^{\mathrm{d}}$ & $0.116^{\mathrm{c}}$ & $0.115^{b}$ & $0.104^{\mathrm{d}}$ & $0.146^{\mathrm{a}}$ & $0.116^{\mathrm{c}}$ & 1000 \\
\hline
\end{tabular}

4. شط الخلايا السرطانية AMN3

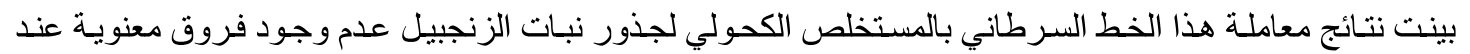

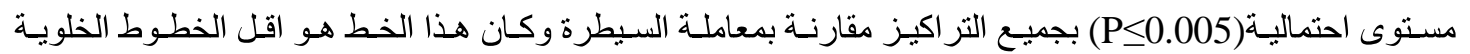
السرطانية تأثراً بالمستخلص و لجميع التر اكيز جدول (1) ، و مايؤكد هذه النتيجة العلاقة المعنوية السالبة للانحدار شكل

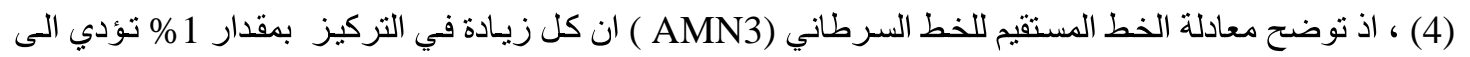
تثبيط في معدل نمو الخط السرطاني بمقدار 0.83\% شكل (4) ، وحسب معادلة التوقع للخط السرطاني شكل(2) و (2) .

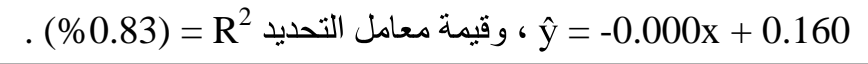

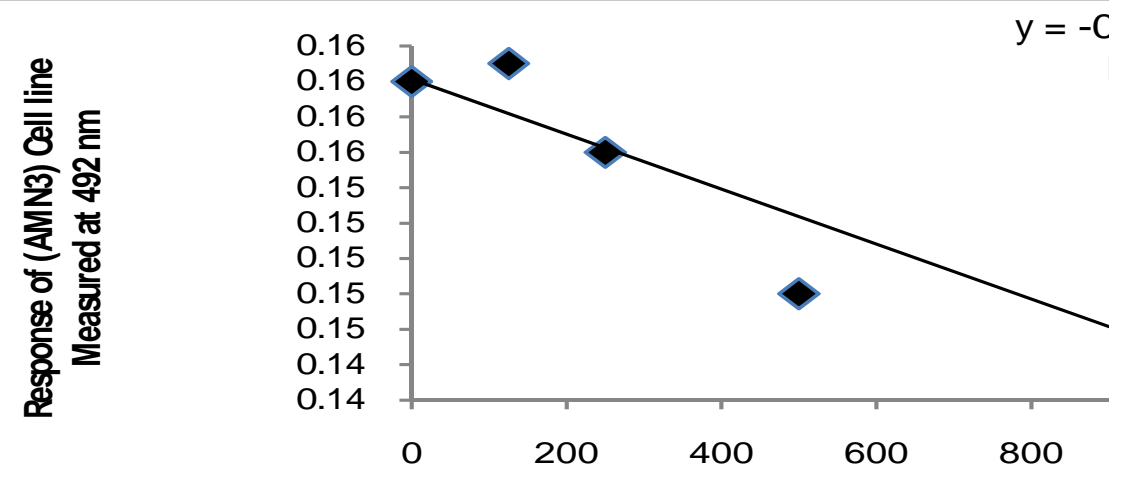

شكل(4) علاقة الانحار بين تراكيز المستخلص النباتي وخط الخلايا السرطاني

5. L الخط الخلوي السرطاني L20B:-

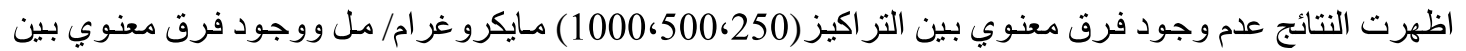

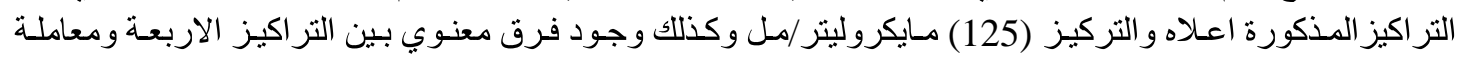

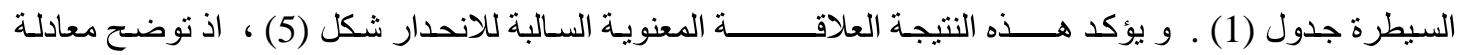

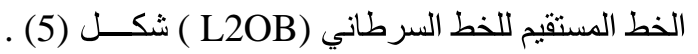

. 0.79$)=R^{2}$ ( ) وقيمة معامل التحديد 


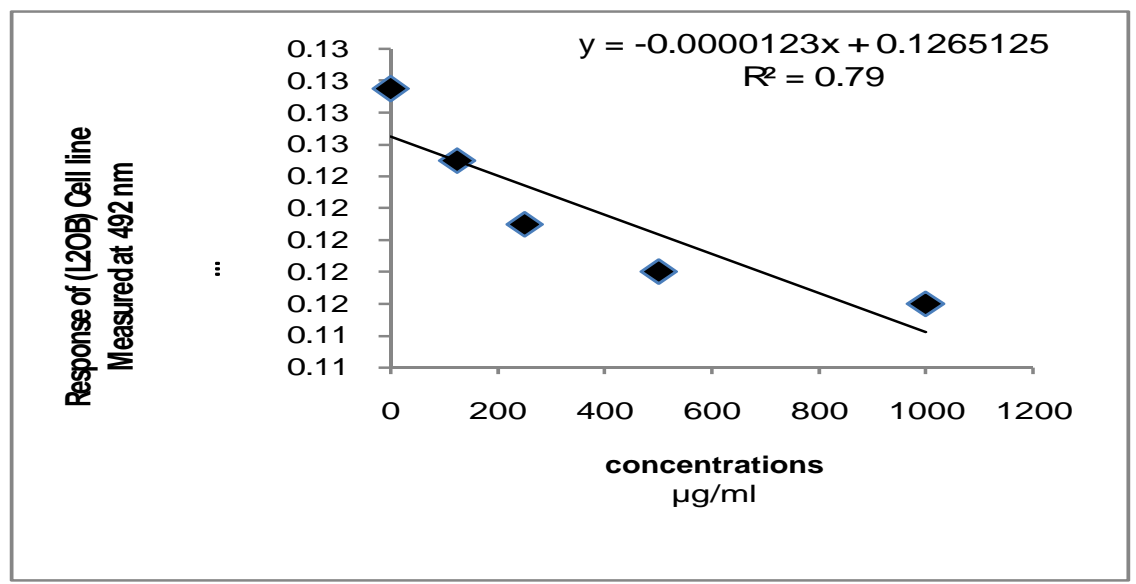

شكل(5) علاقة الاتحدار بين تراكيز المستخلص النباتي والخط الخلوي السرطاني L20B

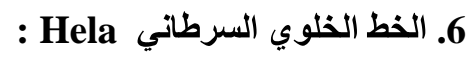

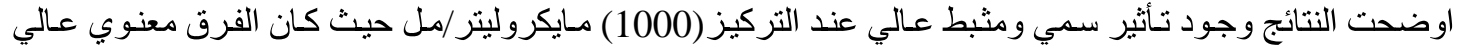

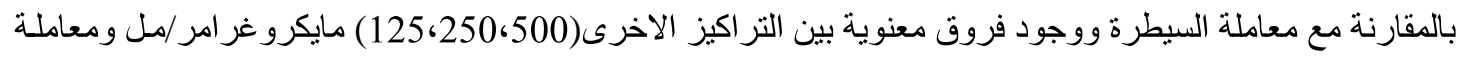
السيطرة و عدم وجود فرق معنوي بين التركيزين(250،

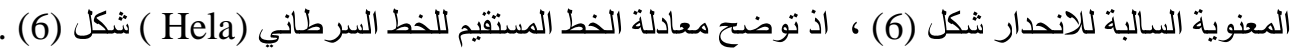

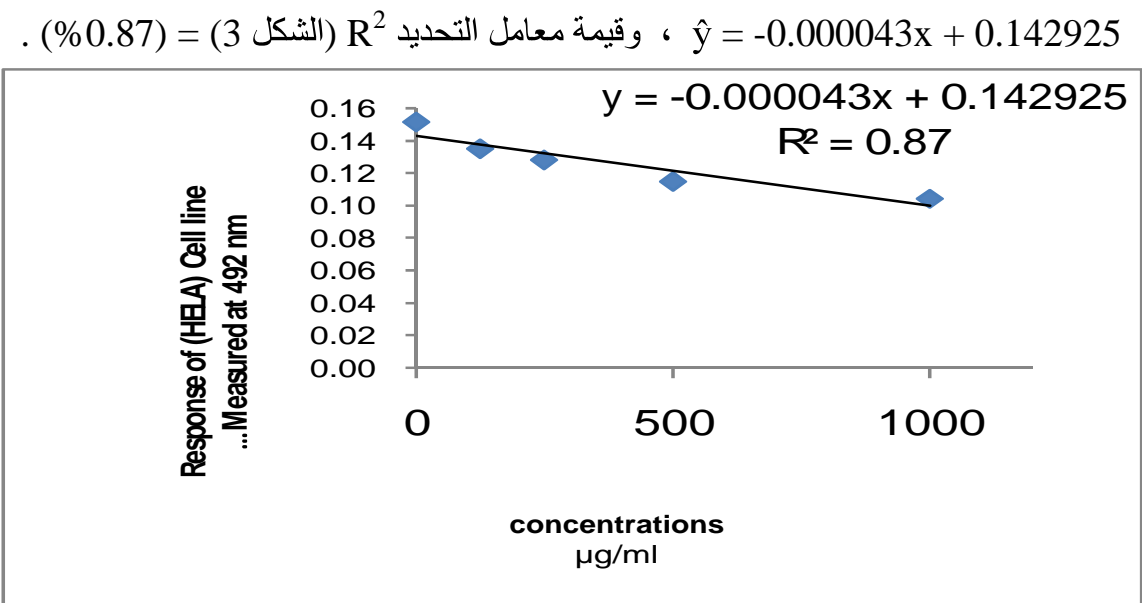

HELA شكل(6)علاقة الانحدار بين تراكيز المسنخلص النباتي والخط السرطاني

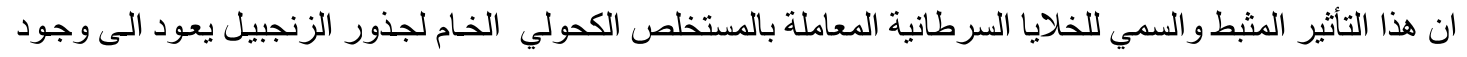

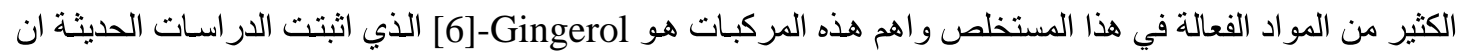

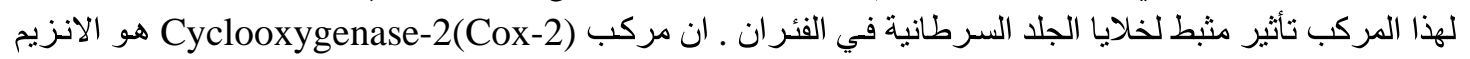

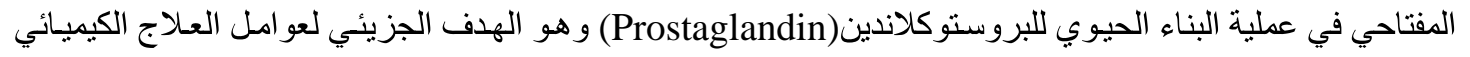

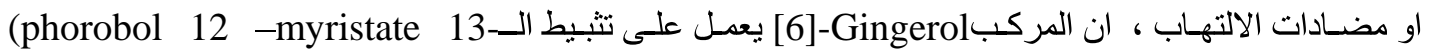

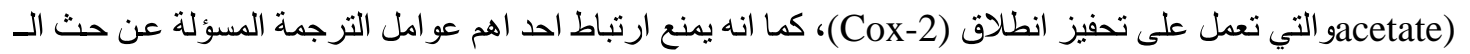

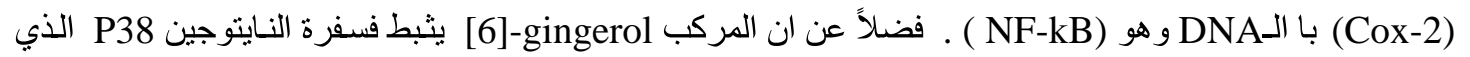

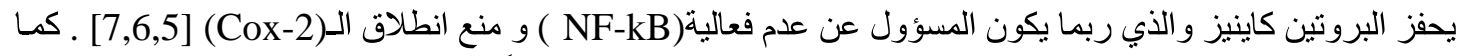

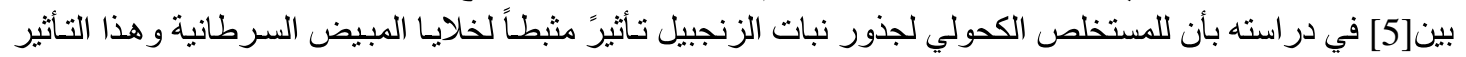




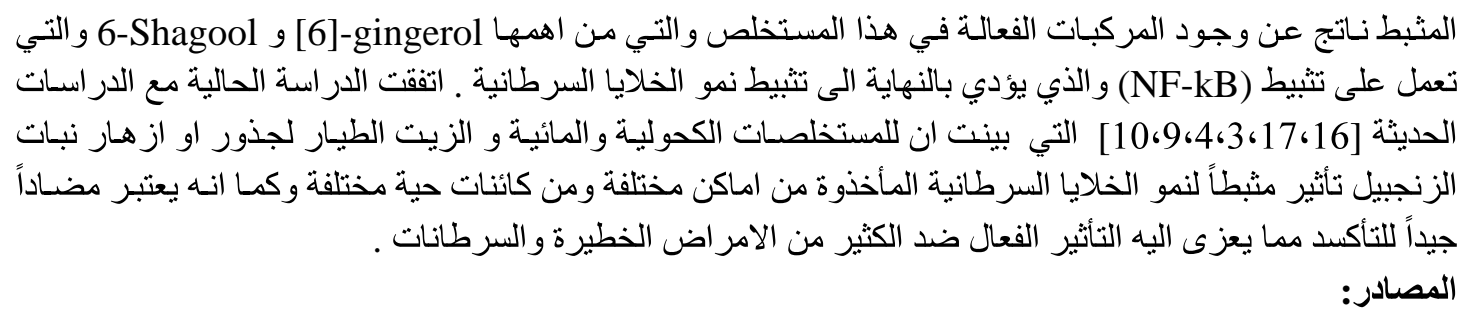

1. Dev,S.(1996).Ancient modern con accordance in ayurvediac plants: Some examples Environ health Prospect, 107:783-789.

2. Guest, E.C.C.Townsen.(1974).Flora of Iraq. Vol. Three. Ministry of Agriculture and Agrarian Reform. Republic of Iraq.

3. Chang CP,Chang JY,Wang FY,Chang JG.(1995). The Effect of Chinase medicinal herb Zingiberis rhizome extract on cytokine secrtion by human peripheral blood mononuclear cells.j.Ethnopharmnaco; 48;13-19.

4. Govindarajan VS. (1982). Ginger-chemistry, technology, and quality evaluation: part 2.Crit.Rev Food Sci Nutr; 17:189-258

5. Kim OS,Chun K,Kundu,KJ,Young-joon,S.(2004).Inhibitory effects of [6]-gingerol on PAM-induced COX-2 Expression and activation of NF-?B and p38 MAPK in mouse Skin.BioFactors;21(1):27-31.

6. Rhode,J,Fogoros,S,Zick,S,Wahl,G,Huang,J,Lui,R.(2007).Ginger inhibits csll growth and modulates anginogenic factors in ovarin cancer cells.BMCComplementar and Alternative Medicine;7(44):1-9.

7. Katiyar,K.S,Agrawal,R,Mukhtar,H,.(1996).Inhibition of Tumor Promotion in SENCAR Mouse Skin by Ethanol Extract of Zingiber officinale Rhizome.Cancer esearch;56:1023-1030.

8. Kim,J,Lee,S,Park,W,H,Yang,H,J,Shin,T,Kim,Y,Baek,N,Kim,S,Choi, S,Kown, eem,K, Jung, M,Kim,D. (2008) .Cytotoxic Compound from the Dried Rhizomes of Zingiber officinale Roscoe.Arch Pharm Res;31(4):415-418.

9. Kalaf,A.,N,Shakya,K.,A,Al-Othman,A,El-Agbar,Z,Farah,H,.(2008).Antioxdant activity of some common plants. Turk J Biol; 32:51-55.

10. Asnani,V,Verma,J,R,.(2006).Aqueous ginger extract Ameliorates paraben induced cytotoxicity.Acta Poloniae Pharmaaceutica-Durg Research ;63(2):117-119.

11. Kazimi,M.;Malik,A.,;Hameed.S.; Akhtar, N. A. and Samina,N.(1994). Ananthraquinon derivative from Cassia italic.Phytochemistry (36)761-763. Simandi,B.;Kery,A.;Kristo, S.T.; Andras, C.; Prechi,A.and Fekete,J.(2001).Supercritical luid extraction of nonvolitile terenoids from medicinal plant.Acta.pharma hung.,71:318-324.

12. Freshney, R. I. (2001). Application of cell culture to toxicology, Cell boil. Toxicol., 17:213-230.

13. Abdul-Majeed, M.R.(2000).Induction and characterization of SU.99 plasmacytoma cell line and its effect on mice immune response.PHD Thesis,Nahrain University.

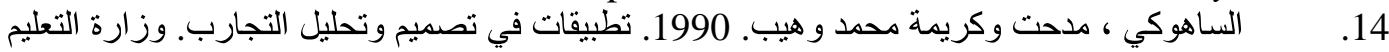

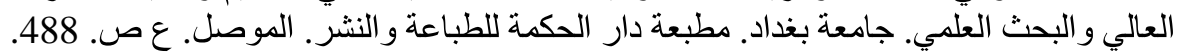

15. Habib,H,S,Makpol,S,AbdulHamid,A,N,Das,S,Ngah,W,Yousf,M,A,Y.(2008). Ginger extract (Zingiber officinale) has anti cancer and anti- inflamentary effect on ethionine-induced hepatoma rats.Clinics;63(6).

16. Anderson ,N.and Lokich, J.J.(1994).Cancer chemotherapy and infusional scheduking. Oncology8(5): 99- 111. 